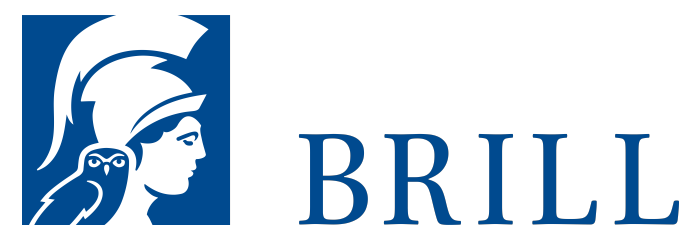

\title{
Der Blick nach innen - Wahrnehmung und Introspektion
}

Author: Johannes Haag

Das Buch beschäftigt sich mit einer traditionsreichen, aber aus der Mode gekommenen Antwort auf die Frage nach dem introspektiven Zugang zu unseren eigenen geistigen Zuständen: Introspektion ist, dieser Antwort gemäß, nach dem Modell der Wahrnehmung der Außenwelt zu konstruieren. Vor dem Hintergrund der gegenwärtigen Diskussion in der repräsentationalistischen Philosophie des Geistes verteidigt das Buch die These von der Introspektion als innerer Wahrnehmung gegen die Kritik von Autoren wie S. Shoemaker und gegen alternative Entwürfe, wie F. Dretskes Theorie der Introspektion als verschobener Wahrnehmung. Aus dem Vergleich konträrer Ansätze in der Erkenntnistheorie und der Philosophie des Geistes geht die ganz und gar antifundamentalistische Philosophie von Sellars als eindeutiger Gewinner hervor.

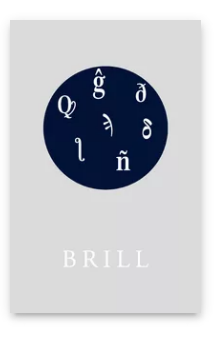

Pages: 355

Seiten

Language:

German

Subjects:

General, Philosophy

Publisher: Brill | mentis

Series:

Geist -

Erkenntnis -

Kommunikation

E-Book (PDF)

Released online:

o1 Jun 2001

ISBN: $978-3^{-}$

95743-915-4

Paperback

Publication date:

o1 Jun 2001

ISBN: 978-3-

89785-058-3 
For more information see brill.com

Order information: Order online at brill.com +44330 333 0049 | customerservices@brill.com Submission information: brill.com/authors

Titles published by Brill | Fink, Brill | mentis or Brill | Schöningh: +49(o)715413279216| brill@brocom.de 